\title{
The Effect of Voice Therapy for the Treatment of Functional Aphonia: A Preliminary Study
}

\author{
No Eul Kim ${ }^{1}$ (D) Jun Seok Kim² (D), Jae Hwan $\mathrm{Oh}^{2}$ (D), Dong Young Kim² (D), and Joo Hyun Woo ${ }^{1,2}$ (D) \\ ${ }^{1}$ Voice-Language Laboratory, Gachon University College of Medicine, Gil Medical Center, Incheon, Korea \\ 2Department of Otohinolaryngology-Head and Neck Surgery, Gachon University College of Medicine, Gil Medical Center, Incheon, Korea
}

기능적 실성증에 대한 음성치료의 효과 분석: 기초 연구

김노을 ${ }^{1}$, 김준석 ${ }^{2}$, 오재환 ${ }^{2}$, 김동영 ${ }^{2}$, 우주현 ${ }^{1,2}$

1 가천대학교 의과대학 길병원 이비인후과 음성언어연구실, ${ }^{2}$ 가천대학교 의과대학 길병원 이비인후과학교실

Background and Objectives Functional aphonia refers to in which by presenting whispering voice and almost producing very high-pitched tensed voices are produced. Voice therapy is the most effective treatment, but there is a lack of consensus for application of voice therapy. The purpose of this study was to examine the vocal characteristics of functional aphonia and the effect of voice therapy applied accordingly.

Materials and Method From October 2019 to December 2020, 11 patients with functional aphonia were treated using voice therapy which was processing three stages such as vocal hygiene, trial therapy, and behavioral therapy. Of these, 7 patients who completed the voice evaluation before and after voice therapy was enrolled in this study. By retrospective chart review, clinical information such as sex, age, symptoms, duration, social and medical history, process of voice therapy, subjective and objective findings were analyzed. Voice parameters before and after voice therapy were compared.

Results In GRBAS study, grade, rough, and asthenic, and in Consensus Auditory-Perceptual Evaluation of Voice, overall severity, roughness, pitch, and loudness were significantly improved after voice therapy. In Voice handicap index, all of the scores of total and sub-categories were significantly decreased. In objective voice analysis, jitter, cepstral peak prominence, and maximum phonation time were significantly improved.

Conclusion The voice therapy was effective for the treatment of functional aphonia by restoring patient's vocalization and improving voice quality, pitch and loudness.

Keywords Dysphonia; Functional aphonia; Voice training; Voice therapy.

\section{서 론}

기능적 음성장애(functional voice disorders)는 성대의 기질적 병변이나 신경학적 병변 없이 목소리에 변화가 나타나는 질환을 의미한다[1]. 이 중에서도 기능적 실성증(functional aphonia)은 연속발화에서 리듬, 운율에 문제를 보이지 않으나 목소리가 약화 (lacking)되어 속삭이는(whisper) 음성으로 나타나며 거의 소리가 없거나 긴장된 목소

\author{
Received March 18, 2021 \\ Revised April 19, 2021 \\ Accepted April 23, 2021
}

\section{Corresponding Author}

Joo Hyun Woo, MD, PhD

Department of Otohinolaryngology-

Head and Neck Surgery,

Gachon University

College of Medicine,

Gil Medical Center,

21 Namdong-daero 774beon-gil,

Namdong-gu, Incheon 21565, Korea

Tel +82-32-460-3324

Fax+82-32-467-9044

E-mail woojh@gilhospital.com

\section{ORCID iDs}

No Eul Kim (D)

https://orcid.org/0000-0002-3605-9253

Jun Seok Kim (1)

https://orcid.org/0000-0002-4203-0131 Jae Hwan Oh (ID)

https://orcid.org/0000-0002-1180-2581

Dong Young Kim (D)

https://orcid.org/0000-0001-5485-7198

Joo Hyun Woo (D)

https://orcid.org/0000-0002-8584-563X

This is an Open Access article distributed under the terms of the Creative

Commons Attribution Non-Commercial License (https://creativecommons.org/ licenses/by-nc/4.0) which permits unrestricted non-commercial use, distribution, and reproduction in any medium, provided the original work is properly cited. 
리로 매우 높은 고음만 짧게 산출된다[2-4].

기능적 음성장애에 대한 명확한 원인은 알려지지 않았지만 급성 후두염, 과도한 음성남용, 외상, 성대 점막의 광범위한 절 제와 같은 수술 후 변화, 갑작스런 스트레스 등이 원인이 될 수 있다[5].

음성치료는 기능적 음성장애의 가장 효과적인 치료방법이 며, 기능적 실성증에서 음성치료 후에 종종 극적이고 신속한 음성향상이 나타나기도 한다. 음성치료의 도입시기는 실성증 이 오래될 경우 음성장애가 더 고착화될 가능성이 높기 때문 에 가능한 조기에 시행되어야 한다[5]. 기능적 실성증의 치료 를 위해선 음성위생 교육, 환경 인식, 상담 등의 간접적인 음 성치료와 정상적인 음성 산출을 위한 생리적 발성, 차폐, 후두 마사지, 성문기능훈련 등이 시행될 수 있다[1,3,6].

기능적 실성증으로 진단되었을지라도 환자 개개인의 음성 특징과 성대 운동 양상이 다르기 때문에 모든 환자에게 일률 적인 치료법을 적용하기는 어렵다. 따라서 환자의 발성 상태 에 따른 문제 요인을 확인 한 후 최적의 음성을 유도하여야 한다. 하지만 환자 개개인의 특성에 따라 어떠한 중재법이 가 장 효과를 보였는지에 대한 연구나 합의는 부족한 실정이다.

이에 본 연구에서는 기능적 실성증 치료에 도움이 되는 자 료를 얻고자 기능적 실성증의 치료 과정에서 파악된 발성 특 징과 이에 따라 적용된 음성치료의 효과를 분석하였으며 문 헌 고찰과 함께 보고하고자 한다.

\section{대상 및 방법}

2019년 10월에서 2020년 12월까지 이비인후과에 내원하여 기능적 실성증으로 진단받고 음성치료를 실시한 11 명의 환자 를 대상으로 하였다. 말(speech)의 운율, 리듬은 정상이지만 속삭이는 음성으로 산출되며 후두스트로보스코피 검사에서 성대운동장애나 기질적인 병변이 관찰되지 않지만 성문폐쇄 부전이 나타나는 환자를 기능적 실성증으로 진단하였다.

후향적 의무기록 분석을 통해 대상자의 성별, 나이, 증상, 증상기간, 음성남용 또는 과용 여부, 정신적 영향 요소, 음주, 흡연, 과거병력, 후두스트로보스코피 소견, 객관적 그리고 주 관적 음성검사 항목 등을 조사하였다. 본 연구는 기관 연구윤 리 심의기구의 허가를 받고 시행하였다(GAIRB2020-459).

음성치료는 진단 후 일주일 내 도입하였고 치료 기간은 주 1-2회(30분간)씩 총 8회기를 시행하였으며 치료 종결 후 3개 월의 추적검사를 진행하였다.

\section{음성분석}

치료 효과 측정을 위해 소음이 통제된 검사실에서 음성치
료 전후 환자의 음성을 녹음하였다. 대상자의 입과 마이크 사 이의 거리는 약 $10 \mathrm{~cm}$ 를 유지한 채 편안한 목소리로 $/$ 아/를 3-4초간 발성하도록 하였다. 또한 연결발화(산책 문단의 첫 번째 문장, 가을 문단)를 수집하였다.

음성샘플의 청지각적 분석을 위해 GRBAS scale로 전반적 음질(grade, G), 조조성(roughness, R), 기식성(breathiness, $\mathrm{B})$, 무력성(asthenic, A), 긴장성(strain, S)을 측정하였다. 또 한 Consensus Auditory-Perceptual Evaluation of Voice $(\mathrm{CAPE}-\mathrm{V})$ 를 통하여 전반적 중증도(overall severity, OS), 조조성(roughness, R), 기식성(breathiness, B), 긴장성(strain, $\mathrm{S}$ ), 음도(pitch, P), 강도(loudness, L)를 측정하였다.

음성장애가 환자의 생활에 미치는 정도를 파악하기 위해 환자 중심의 주관적 자가보고인 음성장애지수(voice handicap index, VHI)를 시행하였다. VHI는 총 점수와 하부영역 인 기능적(functional), 신체적(physical) 감정적(emotional) 으로 나누어 각각 분석하였다.

음향학적 분석을 위해 컴퓨터음성분석(computerized speech lab) (Model 4500, KayPENTAX Elemetrics, Lincoln Park, NJ, USA)의 실시간 음도평가(real-time pitch)와 다면음성분석프로그램(Multi-Dimensional Voice Program) 를 사용하여 기본주파수(fundamental frequency, F0), 주파 수변동률(jitter), 진폭변동률(shimmer), 소음 대 배음비(noise to harmonic ratio) 등을 측정하였다.

켑스트럼분석을 위해 Hillenbrand 등[7]이 개발한 프로그 램을 통해 켑스트럼최대융기(cepstral peak prominence, $\mathrm{CPP}$ )를 측정하였고 모음수준(/아/ 연장발성, $\mathrm{CPP} / \mathrm{a} /$ )과 문장 수준(산책 문단의 첫 번째 문장, $\mathrm{CPPs}$ )에서 각각의 $\mathrm{CPP}$ 값을 구하였다.

공기역학적 검사를 위해 발성공기역학시스템(phonatory aerodynamic system) (Model 6600, KayPENTAX Elemetrics)을 사용하여 최대 연장발성시간(maximum phonation time), 평균호기류율(mean expiratory airflow), 평균성문하 압(mean peak air pressure) 값을 측정하였다.

\section{성대진동검사}

후두스트로보스코피 검사를 시행하여 치료 전후의 성문폐 쇄와 성대진동을 평가하였다. 평가는 경력 10 년 이상된 1 인의 후두음성의학 전문의에 의해 시행되었다. 양측성대의 접촉이 전혀 이루어지지 않는 경우 0 , 성문의 전후 절반 이하에서 접 촉이 이루어지는 경우 1 , 성문의 전후 절반 이상에서 접촉이 이루어지는 경우 2 , 완전 성문폐쇄가 가능한 경우를 3 으로 측정하였다. 성대진동은 진동이 없는 경우 0 , 정상 성대진동 에 비해 두드러지게 감소한 경우 1 , 약간 감소한 경우 2 , 정상 
성대진동을 3으로 측정하였다.

전기생리학적 검사인 전기성문파형검사(electroglottography) (Model 4500, KayPENTAX Elemetrics)를 사용하여 성문폐쇄율(closed quotient)을 측정하였다.

\section{통계 분석}

수집된 자료에 대한 통계학적 분석은 SPSS version 22.0 (IBM Corp., Armonk, NY, USA)을 이용하였다. 평가자 내 신뢰도 검증을 위해 치료 전후 검사 시행 후 2-14일 이내에 재평가를 실시하여 급내상관계수(intraclass correlation $\mathrm{CO}^{-}$ efficient, ICC)를 산출하였고 95\%의 신뢰구간을 설정하여 시행하였다.

환자들의 음성치료 전후 청지각적, 음성자가인식, 음향학 적, 공기역학적, 후두스트로보스코피 소견 및 전기생리학적 수치 비교를 위해 Wilcoxon's signed-ranks test를 사용하였 다. 또한 시도치료에 효과를 보인 환자군과 보이지 않던 환자 군을 나누어 그룹 간 치료 전-후 음향학적, 공기역학적 및 전 기생리학적 수치 비교를 위해 Mann-Whitney U Test를 실 시하였다. 두 검증 모두 유의수준 0.05 수준에서 검정하였다.

\section{음성치료}

음성치료는 3가지 단계에 포커스를 두어 시행하였다(Supplementary Table 1 in the online-only Data Supplement).

첫 번째 단계에서는 음성위생교육을 실시하였고, 음성평가 결과를 설명하며 현재 보이는 음성문제에 대한 설명과 후두 의 구조 및 기능을 설명하였다.

두 번째 단계에서는 시도치료(trial therapy)로 차폐, 생리적 발성 유도, 머리 위치 변경을 시도하였다.

세 번째 직접치료 단계에서는 상체이완운동, 후두마사지를 실시하였고, 발성 시 복식호흡을 사용할 수 있도록 교육하였 다. 이러한 신체적 조건들이 준비되면 반폐쇄성도훈련(semioccluded vocal tract exercise) 중 입술 떨기, 물 저항 빨대 발성(water resistance therapy)을 시행하였다. 차폐나 생리적
발성 유도의 효과가 없고, 반폐쇄성도 훈련 시 발성단계에서 어려움을 보이면 기류산출의 안정화 및 가벼운 기식성 발성 을 유도할 수 있는 방법을 추가적으로 시도하였다[3]. 이러한 방법들을 통해 효율적인 발성이 유도되면 다양한 음도에서 발성을 유도할 수 있는 음도 변화(pitch inflections)와 성대 내전 강화를 위한 성대기능훈련(vocal function exercise)을 실시하였다.

마지막 단계에서는 공명 능력 증대 및 일반화를 위해 허밍, 음성배치, 공명음성훈련을 단어부터 문장까지의 다양한 언어 학적 단위의 자극과제를 제공하여 실시하였다.

\section{결 과}

11 명의 환자 중 치료 전후 음성검사를 시행한 7명의 환자 가 연구에 포함되었다. 대상자의 평균연령 43세 $( \pm 16.4)$ 였고 성별은 남자 1명, 여자 6 명이었다. 주 증상은 갑작스럽게 모 든 상황에서 속삭이는 소리로 나오는 발성이었다. 증상 발현 후 병원에 내원할 때까지 기간은 최소 2주에서 최대 7 개월로 다양하였다. 음성 관련 과거력 조사에서 음성과용자 1 명, 흡연 자 1명이었고 모든 환자에서 음성장애 과거력은 없었다. 치료 횟수는 2 명에서 4 회기, 5 명에서 8 회기가 시행되었다(Table 1).

평가자 내 일치성을 살펴보기 위해 ICC를 95\%의 신뢰구 간을 설정하여 시행하였고 후두스트로보스코피 점수의 ICC 는 0.949 , 청지각적 평가의 ICC는 0.946 이었다.

\section{후두스트로보스코피 검사 결과}

후두스트로보스코피를 이용하여 기능적 실성증 환자들의 치료 전후 성문폐쇄(glottis closure)와 점막파동(mucosal wave)을 비교하였다(Table 2). 통계적으로 유의한 차이는 없 었지만 치료 전 성대접촉 지수는 평균 0.71 , 음성치료 후 접촉 정도는 평균 1.57 로 증가하였다. 성대진동 지수의 경우, 치료 전 평균 1.00 에서 치료 후 평균 1.71 로 증가하였다.

Table 1. Demographys of functional aphonia patients

\begin{tabular}{|c|c|c|c|c|c|c|c|c|c|}
\hline \multirow{2}{*}{ Age } & \multirow{2}{*}{ Sex } & \multirow{2}{*}{ Symptom } & \multirow{2}{*}{ POD } & \multicolumn{5}{|c|}{ Social and medical history } & \multirow{2}{*}{$\begin{array}{c}\text { Sessions of } \\
\text { voice therapy }\end{array}$} \\
\hline & & & & Voice abuse & Stress & Alcohol & Smoking & $\mathrm{Hx}$ & \\
\hline 55 & $\mathrm{~F}$ & Aphonic voice & $2 \mathrm{wk}$ & No & No & No & No & No & 4 \\
\hline 57 & $\mathrm{~F}$ & Aphonic voice & 4 month & No & No & No & No & No & 4 \\
\hline 49 & $\mathrm{~F}$ & Aphonic voice & 5 month & No & No & No & No & No & 8 \\
\hline 56 & $\mathrm{~F}$ & Aphonic voice & 1 month & No & No & No & No & No & 8 \\
\hline 45 & $\mathrm{~F}$ & Aphonic voice & $3 \mathrm{wk}$ & Yes & No & No & No & No & 8 \\
\hline 18 & $\mathrm{~F}$ & Aphonic voice & 7 month & No & No & No & No & No & 8 \\
\hline 22 & $\mathrm{M}$ & Aphonic voice & $2 \mathrm{wk}$ & No & No & No & Yes & No & 8 \\
\hline
\end{tabular}

POD, period of duration; $\mathrm{Hx}$, past medical history related with dysphonia 


\section{주관적 음성분석 결과}

기능적 실성증 환자들의 치료 전 후 GRBAS, CAPE-V 그 리고 VHI의 수치를 각각 비교하였다(Table 3). GRBAS 평가 중 전반적 중증도는 치료 전 평균 2.64에서 치료 후 $1.00(\mathrm{p}=$ $0.018)$, 기식성은 치료 전 평균 2.14에서 치료 후 $0.92(\mathrm{p}=0.042)$, 무력성은 치료 전 평균 2.14에서 치료 후 $0.57(\mathrm{p}=0.026)$ 로 각 각 유의하게 감소하였다. 거친음과 긴장음은 통계적으로 치료 전과 후에 유의한 차이가 없었다. $\mathrm{CAPE}-\mathrm{V}$ 의 치료 전후를 비 교하였을 때 전반적 중증도가 치료 전 평균 73.14에서 치료 후 $26.00(\mathrm{p}=0.018)$, 기식성은 치료 전 평균 56.00에서 치료 후 $22.14(\mathrm{p}=0.028)$, 음도는 치료 전 평균 50.00에서 치료 후 17.43 $(\mathrm{p}=0.018)$, 강도는 치료 전 평균 57.14에서 치료 후 $15.71(\mathrm{p}=$ 0.018)로 각각 유의하게 감소하였다. 거친음과 긴장성은 치료 전후에 통계적으로 유의한 차이는 없었다. 음도는 치료 전 고 음도의 특징이 나타났지만 치료 후 안정적인 음도를 보였고, 강도는 치료 전 약한 강도의 특징이 나타났으나 치료 후 적절 한 강도를 보여 호전되는 양상을 보였다.

$\mathrm{VHI}$ 를 치료 전후 비교하였을 때 기능적 점수는 치료 전 평

Table 2. Comparison of stroboscopic findings before and after treatment

\begin{tabular}{lccc} 
Stroboscopic & Before treatment & After treatment & $\mathrm{p}$ \\
GC & $0.71 \pm 0.95$ & $1.57 \pm 1.13$ & 0.109 \\
MW & $1.00 \pm 0.81$ & $1.71 \pm 0.75$ & 0.059 \\
\hline
\end{tabular}

Data are presented as mean \pm standard deviation. GC, glottis closure; MW, mucosal wave
균 25.14에서 치료 후 $7.57(\mathrm{p}=0.018)$, 신체적 점수는 치료 전 평균 29.71에서 치료 후 $11.43(\mathrm{p}=0.018)$, 감정적 점수는 치료 전 평균 19.00에서 치료 후 $10.86(\mathrm{p}=0.018)$, 총점은 치료 전 평 균 73.86에서 치료 후 $29.86(\mathrm{p}=0.018)$ 으로 모두 통계적으로 각각 유의하게 감소하였다.

\section{객관적 음성분석 결과}

기능적 실성증 환자들의 치료 전후 음향학적, 공기역학적 그 리고 전기생리학적 검사의 수치를 각각 비교하였다(Table 4). 음향학적 검사에서는 주파수변동률이 치료 전 평균 4.27\%에 서 치료 후 $1.56 \%(\mathrm{p}=0.018)$, 강도변동률이 치료 전 평균 $8.38 \%$ 에서 치료 후 $3.47 \%(\mathrm{p}=0.018)$ 로 각각 유의하게 감소하였다. $\mathrm{CPP} / \mathrm{a} /$ 는 치료 전 평균 11.33 에서 치료 후 16.93 ( $\mathrm{p}=0.018$ ), $\mathrm{CPPs}$ 는 치료 전 평균 10.19에서 치료 후 $12.06(\mathrm{p}=0.018)$ 으로 각각 유의하게 증가하였다. 공기역학적 검사에서는 최대연장 발성시간 치료 전 평균 6.27 초에서 치료 후 11.46 초 $(\mathrm{p}=0.018)$ 로 유의하게 증가하였다.

시도치료에서 반응을 보이지 않는 3 명의 환자들은 성문하 압력이 평균 $18.13 \mathrm{~cm} \mathrm{H} \mathrm{H}_{2} \mathrm{O}$ ( $\mathrm{p}=0.034$ ), 성대접촉률이 $56.98 \%$ $(\mathrm{p}=0.034)$ 로 시도치료에 반응한 환자들에 비해 유의하게 높 았다(Table 5).

\section{고 찰}

성대구조 및 신경학적 병변이 없는 기능성 음성장애 환자

Table 3. Comparison of subjective voice evaluation parameters before and after treatment

\begin{tabular}{lccc} 
& After treatment & \\
GRBAS & & & \\
Grade & $2.64 \pm 0.74$ & $1.00 \pm 0.91$ & $0.018^{*}$ \\
Rough & $0.64 \pm 0.47$ & $0.07 \pm 0.18$ & 0.102 \\
Breathy & $2.14 \pm 1.06$ & $0.92 \pm 0.83$ & $0.042^{*}$ \\
Asthenic & $2.14 \pm 1.06$ & $0.57 \pm 0.93$ & $0.026^{*}$ \\
Strained & $1.00 \pm 1.19$ & $0.50 \pm 0.95$ & 0.197 \\
Consensus auditory-perceptual evaluation of voice & & & \\
Overall severity & $73.14 \pm 19.55$ & $26.00 \pm 28.98$ & \\
Roughness & $7.71 \pm 9.82$ & $2.86 \pm 7.55$ & $0.018^{*}$ \\
Breathiness & $56.00 \pm 56.71$ & $22.14 \pm 27.51$ & 0.450 \\
Strain & $27.14 \pm 31.06$ & $12.14 \pm 26.11$ & $0.028^{*}$ \\
Pitch & $50.00 \pm 25.16$ & $17.43 \pm 26.07$ & 0.109 \\
Loudness & $57.14 \pm 16.79$ & $15.71 \pm 25.07$ & $0.018^{*}$ \\
Voice handicap index & & & $0.018^{*}$ \\
Functional & & & \\
Physical & $25.14 \pm 6.98$ & $7.57 \pm 9.53$ & $0.018^{*}$ \\
Emotional & $29.71 \pm 5.31$ & $11.43 \pm 10.84$ & $0.018^{*}$ \\
Total & $19.00 \pm 10.32$ & $10.86 \pm 13.91$ & $0.018^{*}$ \\
\hline
\end{tabular}

Data are presented as mean \pm standard deviation. ${ }^{*} \mathrm{p}<0.05$ in Wilcoxon's signed-ranks test 
의 경우 다양하고 복합적인 원인들이 음성장애의 원인으로 나타날 수 있기 때문에 환자에게 적용할 수 있는 치료기법이 다양하고 광범위하다[8]. 많은 연구들이 진행되어 왔으나 속 삭이는 소리로 산출되는 기능적 실성증의 음성치료 효과를 분석한 연구는 부족하다. 따라서 저자들은 기능적 실성증 환 자에 대해 음성치료가 미치는 효과를 분석해보고자 하였다.

기능적 실성증에서 헛기침, 웃음, 울음 등의 비언어적인 생 리적 발성 유도가 정상적인 발성 산출에 도움이 될 수 있기 때문에 생리적 발성 유도 후 /아/ 소리를 내도록 하였다[5]. 또 한 청각 마스킹도 정상 발성 산출에 도움이 될 수 있기 때문 에 $70 \mathrm{~dB}$ 백색소음을 헤드폰으로 들려주면서 문장을 읽도 록 하였다. 그 결과, 7 명의 환자 중 4명은 시도치료만으로 목 소리가 호전되는 양상을 보였다. 이는 생리적 발성이나 청각 마스킹이 정상적인 발성 산출 방법을 잃어버린 기능적 실성증

Table 4. Comparison of objective voice evaluation parameters before and after treatment

\section{Before treatment After treatment p}

Acoustic

$\begin{array}{lccl}\text { F0 (Hz) } & 259.41 \pm 114.53 & 213.35 \pm 55.96 & 0.398 \\ \text { Jitter (\%) } & 4.27 \pm 3.07 & 1.56 \pm 1.32 & 0.018^{*} \\ \text { Shimmer (\%) } & 8.38 \pm 4.67 & 3.47 \pm 0.86 & 0.018^{*} \\ \text { NHR } & 0.22 \pm 0.13 & 0.11 \pm 0.02 & 0.091 \\ \text { CPP/a/ } & 11.33 \pm 2.75 & 16.93 \pm 4.34 & 0.018^{*} \\ \text { CPPs } & 10.19 \pm 1.44 & 12.06 \pm 1.35 & 0.018^{*}\end{array}$

PAS

$\begin{array}{lccc}\text { MPT }(\mathrm{sec}) & 6.27 \pm 2.87 & 11.46 \pm 4.20 & 0.018^{*} \\ \operatorname{MPAP}\left(\mathrm{cm} \mathrm{H}_{2} \mathrm{O}\right) & 12.33 \pm 6.23 & 10.75 \pm 1.79 & 0.866 \\ \operatorname{MEAF}(\mathrm{mL} / \mathrm{sec}) & 230 \pm 213.54 & 142.85 \pm 85.57 & 0.149\end{array}$

EGG

$$
\text { CQ (\%) }
$$

$51.31 \pm 5.60$

$43.68 \pm 5.2$

0.063

Data are presented as mean \pm standard deviation. ${ }^{*} \mathrm{p}<0.05$ in Wilcoxon's signed-ranks test. F0, fundamental frequency; NHR, noise to harmonic ratio; $\mathrm{CPP} / \mathrm{a} /$, cepstral peak prominence-/a/ phonation; CPPs, cepstral peak prominence-sentence; MPT, maximum phonation time; MPAP, mean peak air pressure; MEAF, mean expiratory airflow; PAS, phonatory aerodynamic system; EGG, electroglottography; CQ, closed quotient

Table 5. Characteristic difference between response group and non-response group for trial voice therapy before treatment

\begin{tabular}{lccc} 
& $\begin{array}{c}\text { Response group } \\
(\mathrm{N}=4)\end{array}$ & $\begin{array}{c}\text { Non-response group } \\
(\mathrm{N}=3)\end{array}$ & $\mathrm{p}$ \\
PAS & & $18.13 \pm 5.14$ & $0.034^{*}$ \\
$\quad \begin{array}{l}\mathrm{MPAP} \\
\left(\mathrm{cm} \mathrm{H} \mathrm{H}_{2} \mathrm{O}\right)\end{array}$ & & & \\
$\mathrm{EGG}$ & & & \\
$\quad \mathrm{CQ}(\%)$ & $47.99 \pm 1.11$ & $56.98 \pm 2.09$ & $0.034^{*}$ \\
\hline
\end{tabular}

Data are presented as mean \pm standard deviation. ${ }^{*} \mathrm{p}<0.05$ in MannWhitney U test. PAS, phonatory aerodynamic system; MPAP, mean peak air pressure; EGG, electroglottography; CQ, closed quotient
환자에서 잘못된 발성노력을 차단함으로써 정상적인 발성 포 인트를 찾는 데 도움이 되기 때문이다[2].

이중진동원을 사용하는 반폐쇄성도훈련의 입술 떨기, 물 저 항 빨대발성을 시행하였는데 입술 떨기의 경우, 성문폐쇄부전 을 향상시키는 효과와 함께 호흡을 일관적으로 유지하게 하 여 성문하압력을 조정하며 과대 혹은 과소내전을 방지하고 성대의 움직임을 강하게 한다[9]. 물 저항 빨대발성 방법은 발 성 시 진동충격을 감소시키고 성대진동 패턴을 안정적으로 변화시킬 수 있을 뿐만 아니라 입술의 진동, 물거품을 통해 환 자에게 시각적인 피드백을 줄 수도 있다[10]. 치료에서는 직경 $4 \mathrm{~mm}$ 빨대, $3 \mathrm{~cm}$ 물 깊이로 훈련하였으며[11], 그 결과 환자들 이 일정한 음도로 15 초 이상 발성을 유지할 수 있었다. 발성이 안정화되면 음도 변화 치료를 통해 성대의 강한 접촉을 피하 면서 다양한 음높이에서 모음을 연장하며 환자의 음도를 변 화시켰고 성대기능훈련을 통해 윤상갑상근, 성대근을 훈련시 켜 성대의 근력을 강화하였다[12,13]. 이를 통해 다양한 음높 이에서도 환자의 발성이 안정화되도록 유도하였으며 성대근 능력을 향상시켜 이를 유지할 수 있도록 하였다. 이후에는 허 밍, 음성배치, 공명 음성치료방법을 사용하여 음절에서부터 문장까지 다양한 언어 단위에서 부드러운 소리 및 공명을 사 용한 발성을 산출하도록 하였다.

일부 환자는 시도치료방법과 반폐쇄성도훈련 모두에서 발 성이 산출되지 않았으며 발성 시 목에 힘이 많이 들어간다고 호소하였다. 이들의 음성검사를 분석한 결과 성대접촉률과 성 문하압이 높다는 특징이 발견되었으며, 이를 통해 발성 시 후 두근의 과긴장이 동반된 것으로 추정할 수 있었다[14-16]. 이들 을 대상으로 기류산출과 가벼운 기식성 발성을 목표로 한 중 재를 추가하였으며, 이후 반폐쇄성도훈련을 다시 시도하자 발성이 동반된 입술 떨기, 발성이 동반된 물 빨대발성을 10 초 이상 산출하는 모습을 보였다. 이러한 과정을 토대로 환자의 청지각적 특징이 속삭이는 발성이며, 후두스트로보스코피 상 성대접촉이 이루어지지 않으나 성대접촉률과 성문하압력이 높고 시도치료에서 어려움을 보이는 환자의 경우 근육의 긴 장이 동반되어 있을 수 있기 때문에 2차적인 문제를 고려하 여 치료가 시행되어야 할 것으로 사료된다. 또한 속삭이는 소 리의 산출은 후두 배치와 저항의 변화와 함께 기류변화가 이 루어진 결과일 가능성도 높다[17]. 따라서 환자가 속삭이는 소 리를 산출하는 증상으로 내원하고 근육의 변화가 동반되었 을 시 그것이 문제의 원인인지 혹은 원인으로 말미암은 결과 인지는 정확히 규명할 수 없지만, 문제를 지속시키는 요인으 로는 작용할 수 있기 때문에 빠른 음성중재를 실시하여 속삭 이는 소리를 제거하는 것이 필요하다.

본 연구결과를 일반화시키기에는 환자의 수가 제한적이며 
대상자의 성별, 유병기간, 병력 등이 다르다는 한계점이 있다. 하지만 환자가 보이는 청지각적 특성, 공기역학적 평가 결과에 따라 치료의 과정을 조절하였으며 이를 토대로 차후 환자의 양상에 따라 더 세밀한 중재를 시행하는 데 도움이 될 것으로 기대한다.

\section{결 론}

기능적 실성증의 치료를 위해 차폐, 생리적 발성, 머리 위치 변경 등을 이용한 시도치료와 상체이완, 후두마사지, 복식호 흡, 반폐쇄성도훈련, 음도변화, 성대기능훈련, 공명음성훈련 등의 직접치료를 시행하였다. 그 결과, 환자들의 음성에 대한 자가인식이 좋아지고 음질과 최대연장발성시간이 향상되는 효과가 나타났다. 그러나 초기 음성평가 시, 성대접촉률과 성 문하압이 높은 실성증 환자들의 경우 부드러운 발성을 위한 음성치료방법을 추가적으로 적용하면 도움이 될 것으로 판단 된다.

중심 단어: 발성장애; 기능적 실성증; 음성훈련; 음성치료.

\section{Supplementary Materials}

The online-only Data Supplement is available with this article at https://doi.org/10.22469/jkslp.2021.32.2.75.

Acknowledgments

None.

Conflicts of Interest

The authors have no financial conflicts of interest.

\section{Authors' Contribution}

Conceptualization: No Eul Kim, Joo Hyun Woo. Data curation: all authors. Formal analysis: all authors. Investigation: No Eul Kim, Joo Hyun Woo, Jun Seok Kim. Methodology: No Eul Kim, Joo Hyun Woo, Jun Seok Kim. Resources: No Eul Kim, Joo Hyun Woo. Writing-original draft: all authors. Writing - review \& edeting: No Eul Kim, Joo Hyun Woo, Jun Seok Kim. Approval of final manuscript: all authors.

\section{REFERENCES}

1. Ruotsalainen JH, Sellman J, Lehto L, Jauhiainen M, Verbeek JH. In- terventions for treating functional dysphonia in adults. Cochrane Database Syst Rev 2007;3:CD006373.

2. Boone DR, McFarlane SC, Von Berg SL. The voice and voice therapy. 7th ed. Boston: Pearson;2005.

3. Stemple JC, Hapner ER. Voice therapy: Clinical case studies. 5th ed. San Diego: Plural Publishing;2019.

4. Wendler J. Lehrbuch der Phoniatrie und Pädaudiologie. Stuttgart: Thieme; 2005.

5. Ali AI, Osama M, Soha EA, El Kholy MR, Mian FU. Successful management of functional aphonia using a modified voice therapy technique: A case series. Egypt J Otolaryngol 2017;33(4):679-84.

6. Behlau M, Madazio G, Oliveira G. Functional dysphonia: Strategies to improve patient outcomes. Patient Relat Outcome Meas 2015;6:24353.

7. Hillenbrand J, Cleveland RA, Erickson RL. Acoustic correlates of breathy vocal quality. J Speech Hear Res 1994;37(4):769-78.

8. Roy N. Functional dysphonia. Curr Opin Otolaryngol Head Neck Surg 2003;11(3):144-8.

9. Cordeiro GF, Montagnoli AN, Nemr NK, Menezes MH, Tsuji DH. Comparative analysis of the closed quotient for lip and tongue trills in relation to the sustained vowel $/ \varepsilon /$. J Voice 2012;26(1):e17-22.

10. Guzman M, Jara R, Olavarria C, Caceres P, Escuti G, Medina F, et al. Efficacy of water resistance therapy in subjects diagnosed with behavioral dysphonia: A randomized controlled trial. J Voice 2017;31(3):385. e1-385.e10.

11. Guzmán M, Castro C, Madrid S, Olavarria C, Leiva M, Muñoz D, et al. Air pressure and contact quotient measures during different semioccluded postures in subjects with different voice conditions. J Voice 2016;30(6):759.e1-759.e10.

12. Angadi V, Croake D, Stemple J. Effects of vocal function exercises: A systematic review. J Voice 2019;33(1):124.e13-124.e34.

13. Meerschman I, Bettens K, Dejagere S, Tetaert L, D’haeseleer E, Claeys $S$, et al. Effect of two isolated vocal-facilitating techniques chant talk and pitch inflections on the phonation of female speech-language pathology students: A pilot study. J Voice 2016;30(6):771.e17-771.e25.

14. Titze IR. Interpretation of the electroglottographic signal. J Voice 1990;4(1):1-9.

15. Liang FY, Yang JS, Mei XS, Cai Q, Guan Z, Zhang BR, et al. The vocal aerodynamic change in female patients with muscular tension dysphonia after voice training. J Voice 2014;28(3):393.e7-393.e10.

16. Konnai R, Scherer RC, Peplinski A, Ryan K. Whisper and phonation: Aerodynamic comparisons across adduction and loudness. J Voice 2017;31(6):773.e11-773.e20.

17. Rubin AD, Praneetvatakul V, Gherson S, Moyer CA, Sataloff RT. Laryngeal hyperfunction during whispering: Reality or myth? J Voice 2006;20(1):121-7. 
Supplementary Table 1. Process of voice therapy

Stage 1

Instructions to therapy participants \& vocal hygiene

1-1. Present basics of voice production

1-2. Present basics of dysphonia

$1-3$. Discussion of the therapy approach

1-4. Inform about vocal misuses and abuse

Stage 2

Trial voice therapy

2-1. Trial to indirect voice therapy

: Masking, redirected phonation, head positioning

Stage 3

Behavioral voice therapy

3-1. This stage conducted when stage 2 helped improve the patient's voice quality

3-1-1. Focus to body posture relaxation

: Upper relaxation exercise, laryngeal massage, respiration training

3-1-2. Focus to efficient phonation

: Lip trill, water resistant therapy

3-1-3. Focus to phonation to do various pitch

: Pitch inflections, vocal function exercise

3-1-4. Focus to improving resonance ability \& generalization

: Humming, vocal focus, resonant voice therapy

3-2. This step added to 3-1 when stage 2 failed and was performed between 3-1-1 and 3-1-2

3-2-1. Focus to airflow release and breathy phonation

: Airflow release (/u/ prolongation, Voiceless Lip trill)

: Breathy phonation (/u/ prolongation, Voiceless to voiced fricatives) 